\title{
Análise da Agroindústria Canavieira nos Estados do Centro-Oeste do Brasil a partir da Matriz de Capacidades Tecnológicas
}

\author{
Angélica Patrícia Sommer Meurer ${ }^{1}$, Pery Francisco Assis Shikida ${ }^{2}$ e \\ Carlos Eduardo de Freitas Vian ${ }^{3}$
}

Resumo: Esta pesquisa analisou a dinâmica tecnológica da agroindústria canavieira no Centro-Oeste do Brasil, a partir da matriz de capacidades tecnológicas. Foram coletados dados primários junto a usinas e destilarias por intermédio da aplicação de questionários (responderam 100\% das unidades de Mato Grosso, 54,5\% de Mato Grosso do Sul e 50\% de Goiás). Como corolário, observou-se que as agroindústrias canavieiras dos três estados dominam grande parte das capacidades tecnológicas na gradação básica e intermediária. Entretanto, no tocante à gradação avançada, houve os menores percentuais de ocorrências nos três estados centro-oestinos. Logo, é necessário que o setor direcione esforços para crescer em P\&D, o que facilitará a criação de novas tecnologias. De modo geral, constatou-se que Goiás apresentou a maior concentração técnica, sobressaindo-se em relação a Mato Grosso e Mato Grosso do Sul em vários perfis da matriz de capacidades tecnológicas.

Palavras-chaves: Agroindústria canavieira, matriz de capacidades tecnológicas, Centro-Oeste.

Abstract: This research analyzed the technological dynamics of the sugarcane agroindustry in the Midwest region in Brazil, through technological capabilities matrix. Primary data were collected from plants and distilleries by means of questionnaires (the results were: $100 \%$ of units in Mato Grosso State, 54.5\%, in Mato Grosso do Sul and 50\%, in Goiás). As a corollary, it was observed that the sugarcane agroindustries from the three states

1. Professora da Pontifícia Universidade Católica do Paraná-PUC/PR-Toledo. Economista e mestre em Desenvolvimento Regional e Agronegócio pela Universidade Estadual do Oeste do Paraná (Unioeste/Toledo).E-mail: angelicameurer@ibest.com.br

2. Professor de Ciências Econômicas do Programa de Pós-Graduação em Desenvolvimento Regional e Agronegócio e do Programa de Pós-Graduação em Economia da Unioeste/Toledo. Pesquisador do CNPq e do Gepec (Grupo de Pesquisa em Agronegócio e Desenvolvimento Regional). E-mail: peryshikida@hotmail.com

3. Doutor em Economia pela Unicamp. Professor Doutor da Esalq/USP. Coordenador do Grupo de Extensão e Pesquisa em História da Agricultura e dos Complexos Agroindustriais (GEPHAC). E-mail: cefvian@usp.br 
dominate a great part of technological capabilities in basic and intermediate gradation. However, regarding advanced gradation, the lowest percentages of occurrences were observed in the three states mentioned before. Therefore, it is necessary that the agroindustry allocates its efforts to improve RED, which will facilitate the creation of new technologies. Overall, it was found that Goiás presented the highest technical concentration, standing out in relation to Mato Grosso and Mato Grosso do Sul in several profiles of the technological capabilities matrix.

Key-words: Sugarcane agroindustry, technological capabilities matrix, Midwest.

Classificação JEL: Q16, O33.

http://dx.doi.org/10.1590/1234-56781806-9479005301009

\section{Introdução}

Atualmente, a economia mundial caracteriza-se por uma acirrada competição entre os países. Nesse contexto, as empresas têm buscado aperfeiçoar e desenvolver suas capacidades de gestão e inovação com o propósito de se manterem competitivas e/ou alcançar novos mercados. No âmbito dessas transformações, a questão tecnológica tornou-se um elemento importante.

Um dos setores que tem recebido forte influência da tecnologia nas últimas décadas, o agronegócio brasileiro, "[...] produz um quarto do Produto Interno Bruto (PIB) nacional e aproximadamente um quinto do emprego total" (BUAINAIN et al., 2013) e convive em um ambiente concorrencial cada vez mais intenso, o que exige um novo modelo de produção focado na otimização da produtividade. Um dos seus destacados setores, a agroindústria canavieira, não foge a esta regra e vem mostrando desempenho econômico derivado de estratégias competitivas como, por exemplo, a intensificação da colheita mecânica de cana-de-açúcar, o uso de variedades mais producentes, o aproveitamento intensivo dos subprodutos desta atividade, a construção de modais alternativos de transporte etc. (TORQUATO et al., 2009; SIQUEIRA, 2013; SHIKIDA, 2013).

O Brasil configura-se como o maior produtor mundial de cana-de-açúcar, tendo produzido, na safra 2012/2013, 588,5 milhões de toneladas de cana, 38,2 milhões de toneladas de açúcar (maior produtor mundial) e 23,2 milhões de $\mathrm{m}^{3}$ de etanol (segundo maior produtor mundial). O estado de São Paulo é o maior produtor nacional de cana-de-açúcar, com 56,06\% da produção, seguido de Goiás $(8,96 \%)$, Minas Gerais $(8,80 \%)$, Paraná $(6,75 \%)$ e Mato Grosso do Sul (6,34\%). Na safra 2012/2013, a região Centro-Oeste foi responsável por 18,07\% da produção brasileira, ocupando a $2^{\text {a }}$ posição no ranking entre as regiões (UNICA, 2014a).

Os dados levantados pela Unica (2014b), bem como o mapeamento com imagens de satélite da região Centro-Sul feito pelo Instituto Nacional de Pesquisas Espaciais (Inpe), indicam expansão de 6,5\% na área de cana-de-açúcar disponível para colheita na safra 2013/2014. Este incremento de área para moagem deve ocorrer principalmente em Mato Grosso do Sul, Goiás e Minas Gerais, resultando daí o interesse por estudar os estados do Centro-Oeste, que contém duas das principais áreas de fronteira agrícola canavieira.

Diante do atual cenário da produção nacional de cana-de-açúcar, evidenciando novas fronteiras com potencial, tem-se como temática deste estudo investigar a dinâmica tecnológica da agroindústria canavieira do Centro-Oeste. As unidades que lá estão instaladas internalizam capacidades tecnológicas que oportunizam o aumento da produtividade em condições satisfatórias? 
Deste modo, utilizou-se o instrumental das capacidades tecnológicas para analisar a agroindústria canavieira em Mato Grosso, Mato Grosso do Sul e Goiás. Justifica-se a importância desta pesquisa pela caracterização dos limites e potencialidades desta importante atividade produtiva.

Isto posto, além desta introdução, apresenta-se na seção 2 uma breve descrição sobre a agroindústria canavieira no Centro-Oeste. $\mathrm{Na}$ sequência é abordada a fundamentação teórica. A metodologia compõe a seção 4, e os resultados e discussão a seção 5, enquanto as considerações finais encerram este trabalho.

\section{Caracterização da agroindústria canavieira no Centro-Oeste}

Os estados que compõem o Centro-Oeste são: Mato Grosso, Mato Grosso do Sul e Goiás; acresce a eles o Distrito Federal - Brasília. De acordo com o Censo realizado em 2010 pelo IBGE, a população total do Centro-Oeste é de 14.058.094, representando $7,25 \%$ da população total do Brasil. O crescimento demográfico é de 1,9\% ao ano e grande parte da população reside em áreas urbanas $(88,8 \%)$, restando apenas $11,2 \%$ que moram na zona rural. Ao todo, o Centro-Oeste possui 446 municípios.

A região Centro-Oeste é a principal área de expansão da cana-de-açúcar no Brasil, visto que, de 2000 a 2010, a área plantada cresceu mais de 219\%, passando de 373.173 hectares (ha) para 1.190.572 ha. Embora o Sudeste ainda represente a principal área de plantio de cana (66\%), os estados do Centro-Oeste já representam 13\%, similar a áreas tradicionais como o Nordeste (UNICA, 2014a).

Neste contexto, faz-se necessário traçar um breve histórico acerca da expansão da cultura canavieira nesta região (Centro-Oeste), que é o objeto de estudo desta pesquisa. Nas décadas de 1960 e 1970, os incentivos por parte do governo federal para a ocupação da região Centro-Oeste refletiram em significativos fluxos migratórios e alterações na forma de ocupação dessas terras, por meio da implementação de técnicas moder- nas nas formas de manejo do cultivo de grãos e na criação de gado, levando à expansão da monocultura de alguns produtos agrícolas, como a cana-de-açúcar (COSTA et al., 2010).

O marco da expansão do setor canavieiro ocorreu a partir da década de 1970, com o processo de internacionalização de capitais e a crise do petróleo que favoreceu o plantio desta cultura para a produção de etanol como combustível (NORONHA e ORTIZ, 2006).

O Programa Nacional do Álcool (Proálcool) foi implementado pelo governo brasileiro em 1975, que tinha como objetivo intensificar a produção de etanol para substituir a gasolina devido à crise mundial do petróleo. Nesse período, o Estado disponibilizou grandes incentivos ao setor canavieiro, tais como: linhas de crédito para compra de terras, montagem de destilarias e modernização da produção (VIAN, 2003).

A partir de 1980, no Centro-Oeste, ancorado nas políticas de expansão das agroindústrias pelas fronteiras agrícolas do País, instalaram-se inúmeras empresas dos mais diversos ramos, entre eles, as agroindústrias canavieiras vindas, algumas delas, de capital do Nordeste e de São Paulo. Como destaca Andrade (1994, p. 135), "os estados de Mato Grosso e Mato Grosso do Sul tornaram-se importantes produtores de cana-de-açúcar e álcool nos últimos 15 anos, em consequência da política do Proálcool".

O período de 1986-1990 ficou conhecido como a fase da desaceleração do Proálcool e crise deste programa, pois o governo reviu as políticas que fomentavam a agroindústria canavieira, $\mathrm{o}$ que resultou na redução dos incentivos federais e na consequente diminuição da rentabilidade dos canaviais (RAMOS, 2002).

Na década de 1990 iniciou-se uma nova etapa para o setor sucroalcooleiro - a desregulamentação do setor - com transformações de ordem institucional, organizacional e tecnológica. Em razão disso, o novo ambiente passou a ser marcado pelo caráter apenas regulador do Estado e pela intensificação dos processos competitivos, alterando sua estrutura de produção (TERCI et al., 2005). 
Tabela 1. Produção de cana-de-açúcar no Centro-Oeste, 1990/1991-2012/2013

\begin{tabular}{cccc}
\hline Safras & $\begin{array}{c}\text { Produção de cana-de-açúcar } \\
\text { (milhões toneladas) }\end{array}$ & Safras & $\begin{array}{c}\text { Produção de cana-de-açúcar } \\
\text { (milhões toneladas) }\end{array}$ \\
\hline $1990 / 91$ & 11.561 & $2002 / 03$ & 30.553 \\
$1991 / 92$ & 11.458 & $2003 / 04$ & 36.284 \\
$1992 / 93$ & 11.725 & $2004 / 05$ & 38.153 \\
$1993 / 94$ & 12.634 & $2005 / 06$ & 35.933 \\
$1994 / 95$ & 14.463 & $2006 / 07$ & 40.834 \\
$1995 / 96$ & 17.744 & $2007 / 08$ & 50.879 \\
$1996 / 97$ & 21.706 & $2008 / 09$ & 62.860 \\
$1997 / 98$ & 23.895 & $2009 / 10$ & 77.233 \\
$1998 / 99$ & 25.432 & $2010 / 11$ & 93.794 \\
$1999 / 00$ & 24.684 & $2011 / 12$ & 92.234 \\
$2000 / 01$ & 22.399 & $2012 / 13$ & 106.376 \\
\hline
\end{tabular}

Fonte: Unica (2014a).

Com o fim da regulamentação governamental, iniciou-se o regime mais próximo de livre mercado, sem subsídios, com os preços do açúcar e etanol passando a ser definidos conforme oscilações de oferta e demanda. Assim, os preços da cana passaram a depender de sua qualidade e da sua participação percentual nos produtos finais.

A Tabela 1 mostra a quantidade de cana-de-açúcar produzida na região Centro-Oeste entre as safras 1990/1991 e 2012/2013. Pode-se observar que a produção de cana-de-açúcar em 1990/91 era de 11,561 milhões de toneladas; no entanto, em 2012/2013, o total produzido já havia aumentado para 106,376 milhões de toneladas, ou seja, crescimento de $820,13 \%$ em duas décadas. A taxa geométrica média de crescimento para a produção de cana-de-açúcar no Centro-Oeste nesse período foi de $10,6 \%$ a. $a^{4}$.

Goiás é atualmente o maior produtor de cana-de-açúcar na região Centro-Oeste, seguido por Mato Grosso do Sul e Mato Grosso. Analisando-se o período de 1990/1991 a 2000/2001, verifica-se crescimento menor da produção em comparação com o período seguinte (2001/2002-2012/2013), ou seja, nesta última fase houve forte elevação da produção canavieira nesta região, seguindo o

4. A estimativa desta taxa está de acordo com o método dos mínimos quadrados. Mais considerações sobre isto, ver: Hoffmann e Vieira (1987). cenário nacional. Alguns autores, como Shikida (2013), relacionam o expressivo crescimento da produção canavieira neste período com o lançamento do flex-fuel em 2003, o aumento das exportações de açúcar e a ampliação do mercado interno desta commodity.

Atualmente, a lavoura de cana-de-açúcar continua em expansão no Brasil. A previsão para a safra 2013/14 é que ocorra aumento de 408 mil hectares (ou 4,8\%) na área plantada em relação à safra 2012/13. São Paulo, Minas Gerais, Goiás e Mato Grosso do Sul devem ser os estados com maior acréscimo de áreas, com 141,4 mil hectares, 106,1 mil, 101,1 mil e 43,5 mil hectares, nessa ordem, sendo que dois destes estados localizam-se na região Centro-Oeste (CONAB, 2013).

Espera-se que a apresentação da matriz de capacidades tecnológicas da agroindústria canavieira centro-oestina possa contribuir para o rumo de novas políticas públicas, na medida em que investimentos possam ser direcionados para gradações, âmbitos ou perfis das capacidades tecnológicas analisadas que porventura apresentem limitações.

\section{Fundamentação teórica}

Esta seção abordará primeiramente tecnologia, inovação e dinâmica tecnológica e seus principais conceitos; seguida da definição de matriz 
de capacidades tecnológicas, que é o fundamento deste trabalho.

\subsection{Tecnologia}

O atual cenário econômico, caracterizado por uma austera competição internacional, de grande necessidade de introdução dos avanços tecnológicos nos processos produtivos e de evolução do sistema econômico, tem feito eclodir nas empresas uma permanente preocupação com o desenvolvimento de estratégias para o aprimoramento da capacidade inovadora, ou seja, tornar os indivíduos, as empresas ou nações mais habilidosas para transformar o aprendizado em valor competitivo (CASSIOLATO e LASTRES, 2000; CORAZZA e FRACALANZA, 2004).

Nesse panorama de competitividade, a tecnologia é considerada uma variável estratégica, isto é, as empresas necessitam conhecer as características da tecnologia que utilizam e do mercado no qual estão inseridas para reduzirem as incertezas, fazendo com que tenham rapidez no processo de tomada de decisão (TIGRE, 2005).

O termo "tecnologia" é conceituado por Dosi (1984) como um conjunto de partes do conhecimento, que podem ser práticos e/ou teóricos, que se aplicam à ideia de sucesso ou imagem de fracasso, e tem por objetivo a sobrevivência num mercado competitivo por meio da busca de novas combinações de processos ou produtos. Esse conjunto abrange desde técnicas, conhecimentos, métodos, procedimentos, experiências e know-how, até mecanismos e ferramentas usados para resolver problemas ou ao menos facilitar a solução dos mesmos.

De modo complementar, observa-se que a busca por novas soluções técnicas contém uma particularidade, isto é, os resultados que daí se originam não são conhecidos ex-ante e a taxa de adoção de uma tecnologia, ou mesmo sua direção, estão associadas às expectativas quanto ao futuro do progresso tecnológico (DOSI, 1984). As escolhas de inovação e investimento envolverão inevitavelmente um relativo grau de incerteza; assim, o mercado funciona como uma espécie de provedor de feedback ao método de geração de novas tecnologias, tolhendo ou legalizando desenvolvimentos prováveis (ROSENBERG, 1982).

\subsection{Inovação tecnológica}

O desenvolvimento econômico de um país atrela-se fundamentalmente à sua capacidade de gerar inovações tecnológicas. Joseph Schumpeter, em 1911, foi um dos primeiros precursores desta ligação entre o desenvolvimento de uma nação e sua capacidade de inovar. A ideia preconizada por este autor é de que a inovação tecnológica é o verdadeiro motor do desenvolvimento econômico. Essas inovações sucedem-se de maneira descontinuada no tempo e originam um processo denominado de "destruição criadora", ou seja, as antigas formas de produção são substituídas pelas novas, pela inovação, seja ela em forma de introdução de um novo produto ou processo no mercado, uma nova fonte de matéria-prima ou um novo método de organizar as empresas. A inovação ocorre como consequência da ação do inovador/empreendedor (SCHUMPETER, 1985).

De acordo com Drucker (1986, p. 45), baseado no referencial da teoria schumpeteriana, "[...] os empreendedores inovam, criam valores novos e diferentes, e satisfações novas e diferentes, convertendo um material em um recurso, ou combinando recursos existentes em uma nova e mais produtiva configuração". Observa-se que o empreendedorismo e a inovação caminham juntos.

Para Schumpeter (1985), a introdução de uma inovação implica em um novo dinamismo para a economia, sendo que os lucros advindos da inovação contribuem para acirrar a competição capitalista, atraindo os imitadores dessa inovação para o mercado.

Posteriormente aos conceitos de Schumpeter, o estudo sobre inovações ganhou destaque na literatura sob o enfoque das concepções neoschumpeterianas ou evolucionárias, que teve Nelson e Winter (1982) e Dosi $(1984,1988)$ como alguns dos principais pensadores.

Tais aprofundamentos teóricos se voltaram para o estudo da firma inovativa. Nelson e Winter 
(1982), por exemplo, deram início a uma investigação apoiada em pensamentos de Schumpeter (1942), além de adaptarem diversos conceitos da biologia evolucionista, procurando incorporar a questão tecnológica à teoria da firma. Dosi (1984; 1988) acrescentou o conceito de estratégia tecnológica, propondo a noção de paradigma e trajetórias tecnológicas como ideia de um padrão de solução de problemas tecnológicos.

\subsection{Dinâmica tecnológica}

A interação entre as condições estruturais e ambientais, que demarcam as possibilidades decisórias das firmas quanto à ocupação de mercados, e as estratégias competitivas selecionadas pelas firmas realizadas sob condições de incerteza, dentro de leques de possibilidades, determinam a evolução das estruturas de mercado (CANUTO, 1991).

Cabe aqui destacar a questão da dinâmica tecnológica incorporada no locus da concorrência, isto é, no eixo firma-mercado; em que a firma é vista como de base técnica mutável, influenciada por inovações introduzidas por intermédio das decisões empresariais estratégicas que se norteiam fortemente nas condições de seleção e de apropriabilidade da inovação sob a forma de lucros, e com a presença não eliminável de incerteza nessas decisões (POSSAS, 1991).

Os padrões de ações e de comportamentos das empresas acarretam modos de fazer as coisas e, se essas ações e comportamentos foram bem-sucedidos no passado, tornam-se aprendizado e visam capacitar a empresa para o futuro (DOSI, 1988). O aprendizado é um item importante do processo de inovação, visto que cria capacidade e estímulo para mudanças tanto para as empresas individuais como para a indústria como um todo, resultando em diminuição de custos e melhor desempenho produtivo.

Desta feita, a essência do mecanismo de resolução de problemas é o aprendizado em que, por intermédio dos conhecimentos adquiridos e acumulados ao longo do tempo, os agentes econômicos terão condições de tomar certas decisões; e estas tornarão novas escolhas buscando preservar o processo dinâmico de mercado e, por consequência, darão origem a novos conhecimentos, tratando-se, portanto, de um ciclo no qual o aprendizado nunca é finito.

O processo de adoção contínua de inovações depende do conhecimento que é acumulado ao longo do tempo pelo processo de aprendizado, que pode ser mediante learning-by-doing (LBD), learning-by-using (LBU), learning-by-searching (LBS) e/ou learning-by-interacting (LBI).

A forma de aprendizado learning-by-doing (aprender fazendo) consiste em situações que ocorrem no nível interno da firma, nas quais novas maneiras de se produzir um determinado bem vão sendo descobertas. No LBU (aprendizado via uso), o enfoque concentra-se no lado do usuário, ocorrendo com mais frequência fora da firma, isto é, a aprendizagem decorrente do uso do produto tem início quando o processo termina. O LBS (aprendizado por pesquisa) engloba todas as atividades de busca por novas tecnologias não internas à firma e, na maior parte dos casos, há existência de infraestrutura de conhecimento e a presença de departamentos e equipes de P\&D. A outra forma, LBI (aprendizado por interação) perpassa pelo fato de os agentes, fornecedores-firma-consumidores, consentirem a troca de informações, ações conjuntas, divisão de responsabilidades, estabelecimento de código e procedimentos etc., que resultam em alterações no status quo dos produtos e processos (ROSENBERG, 1982; LIFSCHITZ e BRITO, 1992; CÁRIO e PEREIRA, 2001).

Em suma, a capacidade tecnológica é um dos determinantes que irá diferenciar as empresas; sendo assim, trata-se de um instrumento importante para a competitividade no mercado. Os conceitos sobre tecnologia, inovação e dinâmica tecnológica que foram sinteticamente abordados até aqui procuram servir de base para a compreensão do conceito fundamental deste trabalho, que é capacidade tecnológica, ressaltando que não existe um arcabouço teórico unívoco necessário ao entendimento da dinâmica tecnológica. 


\subsection{Capacidades tecnológicas}

Este item tem como escopo apresentar a classificação de capacidade tecnológica que foi utilizada neste trabalho. Os conceitos associados às capacidades tecnológicas desenvolveram-se por intermédio da teoria evolucionária do progresso técnico, que tem como principais pensadores Nelson e Winter (1982), Rosenberg (1982), Bell (1984), Dosi e Freeman (1992), Zawislak (1996), dentre outros. Esta teoria nasceu como uma reação à teoria ortodoxa, que considerava que a economia sempre estava em equilíbrio. Entretanto, os evolucionários preconizam o contrário: na maior parte do tempo a economia está em desequilíbrio devido ao seu grande dinamismo (ZAWISLAK, 1996).

A proposta central da teoria evolucionária é que as empresas possuem diferentes capacidades e procedimentos; sendo assim, suas decisões são tomadas das mais variadas formas. O choque destas diferenças gera no mercado a competição entre elas, ocorrendo um processo de seleção das melhores, do qual sobreviverão somente as mais aptas. Neste ponto acontecerá a evolução tecnológica (NELSON e WINTER, 1982).

Dependendo do estágio de desenvolvimento de uma tecnologia, esta pode demonstrar mais ou menos problemas, sejam simples ou complexos. Uma empresa deve ser capaz de resolver seus problemas técnicos. Esta capacidade é compreendida como capacidade tecnológica.

Existem vários conceitos para capacidade tecnológica, porém, destaca-se a definição de Lall (1982, 1987), que a entende como sendo um esforço técnico interno para adquirir o domínio de novas tecnologias, adaptá-las para a realidade local e aperfeiçoá-las. De forma semelhante, Dahlman e Westphal (1982) e Bell (1984) definem capacidade tecnológica como o domínio do conhecimento, atingido mediante o esforço tecnológico para adquirir, adaptar e/ou criar tecnologia. Bell e Pavitt (1993) ampliam os conceitos anteriores, definindo capacidades tecnológicas como os recursos necessários para gerar e gerir a mudança tecnológica, sendo estes contidos em indivíduos (aptidões, conhecimentos e experiência) e sistemas organizacionais.

De acordo com Michellim (2012), em ambas as definições de capacidades tecnológicas estão implícitas o fato de o desenvolvimento tecnológico não ser somente adquirir capabilities para inventar novos processos e produtos, mas adquirir a capability para usar de modo eficaz a tecnologia existente, tendo ganhos produtivos e usando preferencialmente estes ganhos para desenvolver e aprimorar ainda mais a tecnologia em uso.

Lall (1992), com o objetivo de identificar os principais condicionantes e características da dinâmica tecnológica, elaborou uma matriz para analisar as capacidades tecnológicas das empresas. Segundo este autor, há três níveis de capacidade tecnológica, conforme explicitado no Quadro 1 a seguir, sendo eles: o básico "simple routine", o intermediário "adaptive duplicative" e o avançado "innovative risky".

O primeiro nível - a capacidade básica - consiste na capacidade de a empresa solucionar simples problemas rotineiros para manter a eficiência do processo existente.

O segundo nível - a capacidade intermediária - exige alguma melhoria da tecnologia vigente, em linhas gerais, num patamar acima do observado no nível básico, mas não a ponto de deter inteligência e aprendizado de referência. Para isto, deve haver um acúmulo de informações e, além da resolução de problemas, a previsão destes.

Por fim, o terceiro nível - a capacidade avançada - é aquele em que as empresas deverão, além de fazer melhor, fazer diferente o que já se faz bem feito, evoluir ou criar novas tecnologias. É a excelência que o setor possui em termos de modernização. As empresas que detêm esta gradação tecnológica procuram adequar suas trajetórias tecnológicas em face de um contexto de progressivas introduções de inovações, num ambiente de crescente concorrência e internacionalização dos mercados mundiais. 


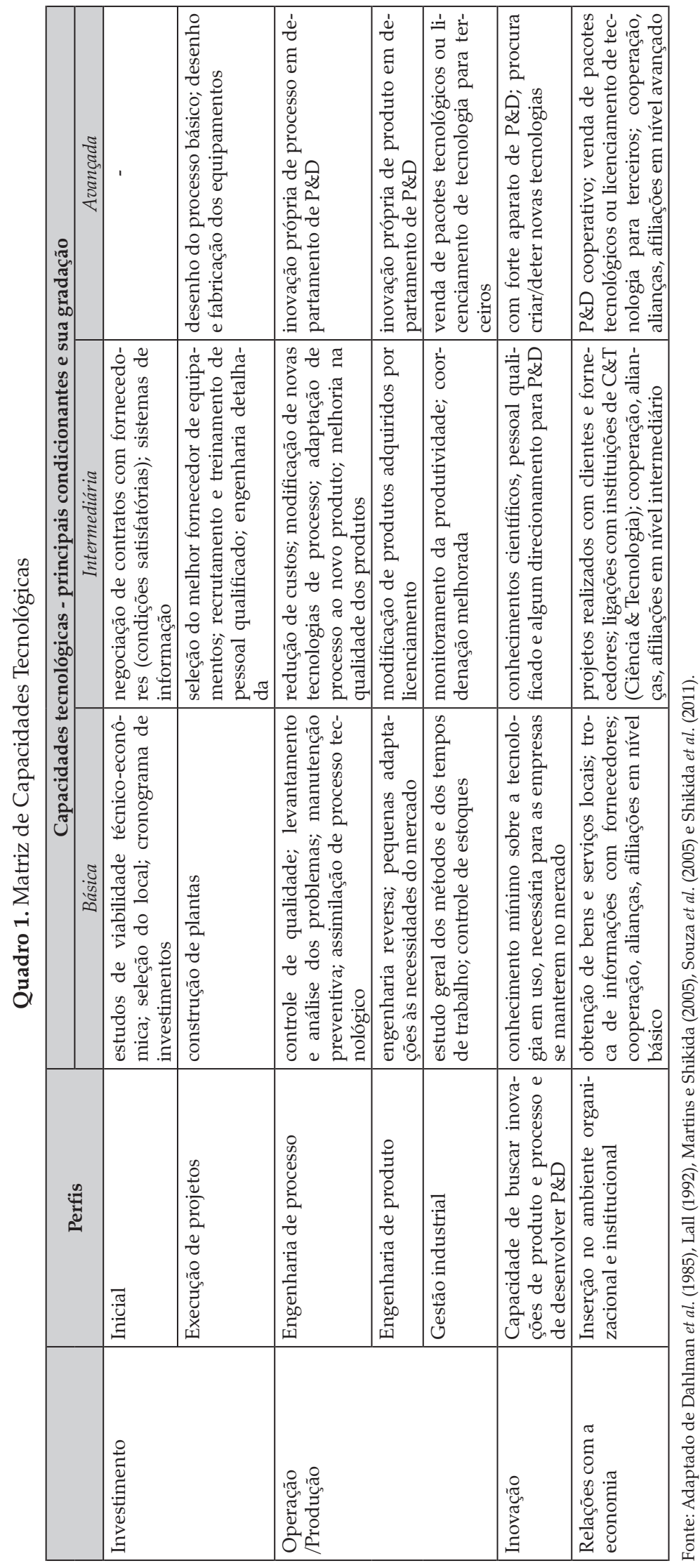

RESR, Piracicaba-SP, Vol. 53, № 01, p. 159-178, Jan/Mar 2015 - Impressa em Abril de 2015 
Na matriz exposta no Quadro 1 destaca-se que os âmbitos das capacidades tecnológicas também possibilitam uma relação com a questão da dinâmica tecnológica, em que as atividades de uma empresa são classificadas em quatro âmbitos, não estanques entre si, a saber:

a) âmbito dos investimentos - divide-se em investimento inicial e execução de projetos;

b) âmbito da operação/produção - divide-se em engenharia de processo, engenharia de produto e gestão industrial;

c) âmbito da inovação - capacidade de buscar inovações de produto e processo e de desenvolver P\&D; e

d) âmbito de relações com a economia inserção no ambiente organizacional e institucional.

As disparidades no desempenho das empresas podem ser interpretadas como consequência das diferenças na acumulação de capacidades tecnológicas (DOSI, 1988). Assim, identificar quais são as capacidades tecnológicas predominantes nas agroindústrias canavieiras dos estados do Centro-Oeste brasileiro, que têm expressiva perspectiva de expansão de sua produção, é importante no sentido de se verificar sobre quais bases se assenta a competitividade centro-oestina, ou seja, se essencialmente na exploração de vantagens derivadas de aptidões edafoclimáticas, condições de mão de obra, ou se está também postada em paradigmas tecnológicos que permitam a elevação da produtividade dos fatores ou o desenvolvimento de novos processos.

Com efeito, de acordo com Coutinho e Ferraz (1994), o sucesso competitivo de uma indústria está relacionado com a dinâmica voltada para a criação e renovação das capacidades tecnológicas que irão conferir vantagens competitivas capazes de mantê-las no mercado. Conforme Canuto (1991, p. 328), a internalização ou apropriação de capacidades tecnológicas nas empresas obedece, em momentos anteriores:

“[...] a alguma estratégia, podendo ter envolvido não apenas expectativas de dinamismo tecnológica e/ou de mercado, como também vantagens na internalização tais como externalidades de aprendizado na interação, atenuação de incerteza quanto aos fluxos comerciais entre setores ou redução do risco de 'oportunismo'".

Conforme observado nesta seção, para as empresas sobreviverem no mercado é necessário um bom aporte de capacidade tecnológica. Isto posto, a seção seguinte trata do referencial metodológico abordado nesta pesquisa.

\section{Metodologia}

Este trabalho caracteriza-se, quanto à natureza, como pesquisa aplicada, que tem por objetivo conceber conhecimentos para aplicação na prática, direcionados à solução de problemas específicos. Com relação à abordagem, ressalta-se que este artigo possui caráter qualitativo-quantitativo. A abordagem qualitativa “[...] tem por objetivo a coleta de elementos não disponíveis, que, ordenados sistematicamente, de acordo com processos adequados, possibilitam o conhecimento de uma determinada situação ou hipótese" (MUNHOZ, 1989, p. 85). Em contrapartida, a abordagem quantitativa busca medir o grau em que algo está presente. Esta metodologia requer o uso de técnicas estatísticas, tais como: média, porcentagem, desvio padrão, moda, mediana, dentre outras. O emprego conjunto da pesquisa qualitativa e quantitativa oportuniza a extração de mais informações do que se poderia obter de maneira isolada (FONSECA, 2002; SCHMIDT, 2006).

No que tange ao objetivo, este trabalho pode ser considerado como de natureza exploratória, pelo fato de esta pesquisa ser realizada sobre um problema ou questão que ainda é pouco conhecido, pouco explorado ou que não tem nenhum estudo anterior a seu respeito, bem como de natureza descritiva, pelo fato de se procurar descrever/analisar o nível tecnológico da agroindústria canavieira no Centro-Oeste do Brasil, por meio do instrumental das capacidades tecnológicas. 
Quanto aos procedimentos metodológicos adotados, este trabalho teve origem numa pesquisa de dados secundários que consistiu primeiramente em apresentar dados da produção mundial e brasileira a respeito da cana-de-açúcar, do açúcar e do etanol, além de caracterizar a agroindústria canavieira no Brasil e, mais especificamente, no Centro-Oeste. Foram utilizados dados fornecidos por órgãos governamentais, entidades representativas do setor, publicações científicas e outros materiais impressos, com o intuito de auxiliar na interpretação da evolução do setor.

Após a caracterização desse setor produtivo, buscou-se apontar qual é a matriz de capacidades tecnológicas das usinas processadoras de açúcar e etanol no Centro-Oeste brasileiro. Sendo assim, a segunda parte baseou-se numa pesquisa de campo, contendo questionário para processamento de coleta de dados primários junto a empresas do setor canavieiro na região centro-oestina; foram selecionadas todas as agroindústrias canavieiras que se localizam nos três estados produtores do Centro-Oeste, a saber: Mato Grosso, Mato Grosso do Sul e Goiás - não há unidades produtivas no Distrito Federal.

O questionário empregado neste estudo baseou-se na matriz de capacidades tecnológicas demonstrada no Quadro 1, sendo respondido pelos executivos/diretores das agroindústrias canavieiras que participaram das assembleias que ocorreram nas estruturas do Sindicato da Indústria de Fabricação de Etanol do Estado de Goiás (SIFAEG) e Sindicato das Indústrias Sucroalcooleiras do Estado de Mato Grosso (Sindálcool), com exceção da Associação dos Produtores de Bioenergia de Mato Grosso do Sul (Biosul), em que este mesmo questionário foi aplicado individualmente ${ }^{5}$.

5. A aplicação do questionário ocorreu em julho, agosto e setembro de 2013 e consistiu em uma entrevista estruturada, ou seja, que seguiu um roteiro previamente estabelecido, com questões que facilitaram descrever as especificidades dos quatro âmbitos norteadores das capacidades tecnológicas - operação/produção; investimento; inovação e âmbito das relações com a economia.
Tendo em vista o levantamento dos dados, o passo seguinte foi fazer a tabulação estatística destas informações. O processo de tabulação resume-se no agrupamento e contagem de todos os casos que estão nas diversas categorias de análise, ou seja, a tabulação consiste na robusta contagem das frequências das categorias de cada conjunto (GERHARDT e SILVEIRA, 2009).

Vale lembrar que esta pesquisa amostral foi por acessibilidade e, de acordo com compromisso firmado a priori e durante a aplicação do questionário, a análise estatística dos dados foi realizada de maneira agregada, por estado, não revelando características particulares de uma ou outra usina/destilaria 6 .

No intuito de analisar os dados obtidos, inicialmente cada usina foi relacionada a um grupo econômico ao qual pertence, agrupando-as. Depois, as mesmas foram identificadas por estado federativo. Em um segundo momento, a partir deste agrupamento, para cada pergunta foi levantada a quantidade de respostas positivas e atribuiu-se um percentual de ocorrência para cada questão.

\section{Resultados e discussão}

Convém destacar que este estudo foi realizado para um universo de 67 usinas e/ou destilarias, contemplando porte grande, médio e pequeno. Em Mato Grosso, das 9 unidades pesquisadas, $100 \%$ responderam ao questionário; em Mato Grosso do Sul, das 22 unidades pesquisadas, o percentual de respondentes foi de $54,5 \%$; em Goiás, das 36 unidades, o índice de respondentes foi de $50 \%$. Este percentual de respostas pode ser considerado satisfatório à luz da literatura de técnicas de pesquisa em economia (GIL, 2000); ademais, frisa-se que são muitas as

6. Com vistas a revelar as dificuldades de obtenção de respostas durante pesquisa similar, a seguir apresenta-se um trecho respondido (cópia textual) por um dos pesquisados: Por norma interna da empresa, a unidade ' $\mathrm{X}$ ' não divulga informações de caráter estratégico elou política de trabalho da companhia. Agradecemos o interesse por nossa opinião e lamentamos não poder contribuir com as informações solicitadas. 
dificuldades encontradas para se obter dados que revelam características competitivas de um importante setor da economia nacional, mormente da agroindústria canavieira (SOUZA et al., 2005).

A Tabela 2 sintetiza os principais resultados obtidos pela coleta de informações via questionário aplicado, em que se apresentam os percentuais de ocorrências a respeito da matriz de capacidades tecnológicas da agroindústria canavieira de Mato Grosso, Mato Grosso do Sul e Goiás.

\section{1. Âmbito do investimento}

Conforme se pode verificar, $100 \%$ das unidades pesquisadas nos três estados dominam o estágio básico do perfil inicial (estudos de viabilidade técnico-econômica; seleção do local; cronograma de investimentos) e execução de projetos no âmbito dos investimentos (construção de plantas). A decisão de localização pertinente ao investimento de uma agroindústria canavieira é muito importante e deve ser amparada por estudos consistentes de viabilidade técnico-econômica, dado que os ativos compreendidos nesta transação possuem alta especificidade de localização; a plantação de cana-de-açúcar a mais de $50-70 \mathrm{~km}$ da usina inviabiliza economicamente esta atividade. Devem ser considerados ainda os acessos aos recursos hídricos, proximidade dos fornece- dores, impostos e legislação ambiental, condições de infraestrutura de transporte etc.

Constata-se que $100 \%$ dos respondentes de cada estado têm capacidades tecnológicas necessárias para a realização de investimentos iniciais no estágio intermediário. Entende-se assim, e não era de se esperar algo diferente, que as usinas e/ ou destilarias, quando da efetivação de um investimento inicial qualquer, baseiam-se na negociação de contratos com fornecedores e consultas a sistemas de informação, seleção do melhor fornecedor de equipamentos, recrutamento e treinamento de pessoal qualificado e engenharia detalhada.

De acordo com a classificação de Lall (1992), e para o âmbito de investimento, presume-se que a empresa que realiza as atividades equivalentes à gradação intermediária terá requisitos necessários para desempenhar as atividades correspondentes à capacidade básica.

Não obstante, no que diz respeito ao nível de gradação avançada, âmbito de investimentos, a matriz expõe pela primeira vez as diferenças que existem em termos de capacidades tecnológicas entre Mato Grosso $(87,5 \%)$, Mato Grosso do Sul $(12,5 \%)$ e Goiás $(61,5 \%)$, concernentes à questão do desenho do processo básico, desenho e fabricação dos equipamentos. Isto demonstra que algumas unidades diferenciam-se das demais apesar de conviverem no mesmo contexto regio-

Tabela 2. Matriz de capacidades tecnológicas da agroindústria canavieira de Mato Grosso, Mato Grosso do Sul e Goiás, segundo percentual de ocorrências

\begin{tabular}{|c|c|c|c|c|c|c|c|c|c|c|}
\hline \multirow{3}{*}{ Âmbitos } & \multirow{3}{*}{ Perfis } & \multicolumn{9}{|c|}{ Capacidade tecnológica (\% de ocorrências) } \\
\hline & & \multicolumn{3}{|c|}{ MT } & \multicolumn{3}{|c|}{$M S$} & \multicolumn{3}{|c|}{ GO } \\
\hline & & Bás. & Inter. & $A v$. & Bás. & Inter. & $A v$. & Bás. & Inter. & $A v$. \\
\hline \multirow{2}{*}{ Investimento } & Inicial & 100 & 100 & - & 100 & 100 & - & 100 & 100 & - \\
\hline & Execução de projetos & 100 & 100 & 87,5 & 100 & 100 & 12,5 & 100 & 100 & 61,5 \\
\hline \multirow{3}{*}{$\begin{array}{l}\text { Operação/ } \\
\text { Produção }\end{array}$} & Engenharia de processo & 100 & 100 & 25 & 100 & 87,5 & 25 & 84,6 & 84,6 & 61,5 \\
\hline & Engenharia de produto & 50 & 0 & 37,5 & 50 & 25 & 37,5 & 38,5 & 53,8 & 61,5 \\
\hline & Gestão industrial & 100 & 87,5 & 0 & 100 & 100 & 0 & 84,6 & 100 & 0 \\
\hline Inovação & $\begin{array}{l}\text { Capacidade de buscar inova- } \\
\text { ções de produto e processo e } \\
\text { de desenvolver P\&D }\end{array}$ & 100 & 75 & 12,5 & 100 & 75 & 12,5 & 92,3 & 76,9 & 46,2 \\
\hline $\begin{array}{l}\text { Relações com } \\
\text { a economia }\end{array}$ & $\begin{array}{l}\text { Inserção no ambiente organiza- } \\
\text { cional e institucional }\end{array}$ & 100 & 75 & 0 & 87,5 & 75 & 12,5 & 92,3 & 84,6 & 23,1 \\
\hline
\end{tabular}

Fonte: Dados da pesquisa. 
nal. O menor percentual apresentado por Mato Grosso do Sul neste item pode ser explicado pelo fato de que as unidades lá instaladas adquirirem de terceiros os equipamentos necessários ao processo produtivo, em função, sobretudo, de sua proximidade física com o estado de São Paulo. Ao revés, as usinas que se localizam em regiões mais distantes deste polo de máquinas e equipamentos para a agroindústria canavieira procuram aperfeiçoar a capacidade de conservação e reparos nos equipamentos ou processos para evitar a suspensão das atividades por muito tempo, explicando, assim, os altos percentuais para Mato Grosso e Goiás para o perfil em questão. Este aspecto já havia sido ressaltado por Vian (2003), sendo agora corroborado para o Centro-Oeste.

\section{2. Âmbito da operação/produção}

No âmbito da operação/produção, no perfil de engenharia de processo, também se percebem algumas diferenças em termos de capacidades tecnológicas para os estados pesquisados. Mato Grosso e Mato Grosso do Sul dominam 100\% da gradação básica. Isto demonstra que as unidades entrevistadas nestes dois estados possuem as capacidades tecnológicas necessárias para a realização das atividades rotineiras que se traduzem em controle de qualidade, levantamento e análise dos problemas, manutenção preventiva e retenção de processo tecnológico. Já em Goiás apenas duas das usinas entrevistadas sinalizaram que não executam tais atividades, o que faz com que este estado tivesse um percentual de $84,6 \%$. Com efeito, isto pode vir a prejudicar o desempenho dessas unidades produtivas porquanto atitudes como a manutenção preventiva dos equipamentos podem reduzir custos, evitando também imprevistos, tais como uma possível parada não programada durante a moagem no período da safra.

Ainda no âmbito da operação/produção e perfil engenharia de processo, destacando agora a gradação intermediária, Mato Grosso apresentou domínio de $100 \%$ neste quesito, enquanto que Mato Grosso do Sul e Goiás exibiram percentuais também altos e muito próximos, 87,5\% e 84,6\%, respectivamente. Esta gradação está relacionada à redução de custos, modificação de novas tecnologias de processo, adaptação de processo aos novos produtos e melhoria na qualidade dos produtos. Contudo, no tocante à gradação avançada, que engloba a inovação própria de processo em departamento de P\&D, em Goiás, $61,5 \%$ das unidades pesquisadas figuram neste nível, ao passo que nos outros dois estados esse número foi de apenas $25 \%$.

Neste panorama, se nota uma importante vantagem competitiva para as unidades produtivas do estado de Goiás frente a Mato Grosso do Sul e Mato Grosso, isto no contexto geral da operação/produção e perfil engenharia de processo, pois a inovação própria de processo em departamento de P\&D é uma das grandes responsáveis pelas melhorias observadas no desempenho econômico das sociedades industriais e, particularmente, das empresas, conforme citou Dosi e Freeman (1992).

Dando sequência à análise da Tabela 2, quanto ao perfil engenharia de produto, verifica-se que a engenharia reversa e pequenas adaptações às necessidades do mercado são práticas pouco comuns ${ }^{7}$ na agroindústria canavieira do Centro-Oeste, pois Mato Grosso e Mato Grosso do Sul apresentaram 50\% deste tipo de engenharia, e Goiás, apenas 38,5\%. Para a gradação intermediária, que trata de modificação de produtos adquiridos por licenciamento, Mato Grosso não apresentou ocorrência, enquanto que Mato Grosso do Sul acusou 25\% desta engenharia e Goiás se sobressaiu com 53,8\% neste quesito. Quando se ressalta a gradação avançada, repete-se o mesmo destaque observado para Goiás $(61,5 \%)$ frente a Mato Grosso $(37,5 \%)$ e Mato Grosso do Sul $(37,5 \%)$. Vale dizer que mesmo

7. "Isto está relacionado ao fato de os dois principais produtos da agroindústria canavieira, o açúcar e o álcool, apresentarem maiores oportunidades de ganhos em redução de custos, por meio de melhorias no processo de produção, do que em diferenciação de produto, dadas as características da demanda, que se fundamenta em características intrínsecas e objetivas desses produtos" (SHIKIDA et al., 2011, p. 615-616). 
não sendo um expediente tão utilizado como a engenharia de processo, a engenharia de produto em Goiás mostrou maior tendência para inovações nos produtos. Não é de se estranhar que este estado esteja hoje ocupando o segundo lugar no ranking de produção nacional de cana-de-açúcar, agora destoando por tentativas de inovação no produto.

No que tange ao perfil da gestão industrial, âmbito operação/produção, não houve ocorrência nos três estados para a gradação avançada. Isto demonstra que não acontece a venda de pacotes tecnológicos ou licenciamento de tecnologia para terceiros na agroindústria canavieira do Centro-Oeste. Contudo, 100\% dos entrevistados em Mato Grosso e Mato Grosso do Sul realizam as capacidades tecnológicas compreendidas no nível básico, ou seja, efetuam o estudo geral dos métodos e dos tempos de trabalho e controle de estoques; para Goiás este índice é próximo, totalizando $84,6 \%$ dos respondentes. Na gradação intermediária, $100 \%$ das unidades entrevistadas em Mato Grosso do Sul e Goiás assinalaram este quesito, enquanto que Mato Grosso apresentou índice de $87,5 \%$, ou seja, nos três estados estudados existe num percentual expressivo o monitoramento da produtividade e coordenação melhorada.

Após análise do âmbito da operação/produção, faz-se necessário realçar aqui uma constatação que coaduna com o referencial teórico, ou seja, aspectos como o controle da qualidade, manutenção preventiva, controle e monitoramento da produtividade, redução de custos etc., evidenciam para a agroindústria canavieira uma forte tendência de aprendizado derivado do "fazer" (learning-by-doing), que consiste em situações que perscrutam novas maneiras de se produzir um determinado produto e de se obter avanços e melhorias no desempenho do processo/gestão/operação desta atividade produtiva.

\section{3. Âmbito da inovação}

No âmbito da inovação, perfil da capacidade de buscar inovações de produto e processo e de desenvolver P\&D, percebeu-se que $100 \%$ das unidades entrevistadas em Mato Grosso e Mato Grosso do Sul apresentam capacidades tecnológicas de gradação básica, que diz respeito ao conhecimento mínimo sobre a tecnologia em uso, indispensável para as empresas se manterem no mercado; em Goiás, este índice foi de 92,3\%. No nível intermediário - conhecimentos científicos, pessoal qualificado e algum direcionamento para P\&D - os três estados acusaram um índice semelhante: Mato Grosso e Mato Grosso do Sul (75\%) e Goiás (76,9\%). Entretanto, na gradação avançada deste mesmo perfil, âmbito da inovação - que engloba a criação ou detenção de novas tecnologias com forte aparato de P\&D - Goiás foi o destaque com 46,2\%, seguido mais de longe por Mato Grosso e Mato Grosso do Sul, com apenas 12,5\%.

\section{4. Âmbito das relações com a economia}

Concernente ao perfil inserção no ambiente organizacional e institucional que pertence ao âmbito das relações com a economia, nesta matriz percebeu-se que as agroindústrias canavieiras entrevistadas diminuem seus percentuais de ocorrência conforme as gradações avançam do nível básico para o intermediário e deste para o avançado. Neste âmbito e perfil, os percentuais dos três estados na gradação básica foram muito próximos: Mato Grosso obteve $100 \%$, Mato Grosso do Sul, 87,5\% e, Goiás, 92,3\%. Isto quer dizer que grande parte das usinas ou destilarias presentes nesses estados costuma adquirir bens e serviços locais, trocam informações com fornecedores, realizam alianças e afiliações em nível básico. Também ocorreu cenário semelhante na gradação intermediária, pois Mato Grosso e Mato Grosso do Sul atingiram percentual de $75 \%$ cada um, enquanto que Goiás alcançou $84,6 \%$. Diante desse resultado, pode-se afirmar que um grande número das unidades pesquisadas em cada estado realizam projetos com clientes e fornecedores, tendo ligações com instituições de C\&T. Neste caso a referência é o CTC (Centro de Tecnologia Canavieira), que atende grande parte da demanda das usinas e destilarias do Brasil no tocante à C\&T (CTC, 2013), além de alianças e 
afiliações em nível intermediário. Na gradação avançada, Mato Grosso não apresentou ocorrência nesse quesito e os percentuais de ocorrências nesse nível para Mato Grosso do Sul e Goiás foram de, respectivamente, $12,5 \%$ e $23,1 \%$; ou seja, observou-se que quase não ocorreu a venda de pacotes tecnológicos ou licenciamento de tecnologia para terceiros, nem P\&D cooperativo ou alianças e filiações em nível avançado. Goiás foi o que mais destoou neste quesito, em função de existências de plantas industriais de capital internacional que priorizam este aspecto.

Observa-se aqui, com maior ênfase para as gradações básica e intermediária, outra forma de aprendizado conhecido como learning-by-interacting, citado por Rosenberg (1982), que perpassa pelo fato de os fornecedores-firma-consumidores consentirem a troca de informações, ações conjuntas, divisão de responsabilidades, estabelecimento de código e procedimentos etc.

Ainda no contexto abordado das relações com a economia, perfil da inserção no ambiente organizacional e institucional, convém ressaltar o importante trabalho que instituições como Sindálcool, Biosul e Sifaeg representam para este setor, porquanto procuram promover encontros entre os associados com o propósito de atualizar os conhecimentos de técnicas e sistemas, almejando a melhoria de rendimento e qualidade da produção, além da troca de informações com for- necedores e clientes. Também coordenam ações institucionais junto aos poderes públicos federal, estadual e municipal, entidades de classe, segmentos empresariais, instituições etc.

\subsection{Análise da ocorrência dos maiores percentuais}

No intuito de dimensionar qual é a gradação tecnológica predominante nos três estados produtores de cana-de-açúcar na região Centro-Oeste do Brasil e qual a sua implicação, observa-se, na Tabela 3, as áreas hachuradas que enfatizam onde estão localizados os maiores percentuais de ocorrências num cotejo entre os três estados pesquisados.

Evidenciou-se que as usinas e destilarias dos três estados dominam grande parte das capacidades tecnológicas na gradação básica e intermediária. Porém, merece destaque o estado de Goiás que apresentou, na maioria das vezes, os percentuais mais elevados de ocorrências na gradação avançada, que retrata maior dinâmica competitiva, a saber: perfil de engenharia de processo; engenharia de produto; capacidade de buscar inovações de produto e processo e de desenvolver P\&D; e perfil inserção no ambiente organizacional e institucional.

Com efeito, Goiás, além de deter o segundo lugar na produção nacional de cana-de-açú-

Tabela 3. Matriz de capacidades tecnológicas da agroindústria canavieira de Mato Grosso, Mato Grosso do Sul e Goiás, segundo os maiores percentuais de ocorrências comparativamente a cada gradação dos três estados

\begin{tabular}{|c|c|c|c|c|c|c|c|c|c|c|}
\hline \multirow{3}{*}{ Âmbitos } & \multirow{3}{*}{ Perfis } & \multicolumn{9}{|c|}{ Capacidade tecnológica (\% de ocorrências) } \\
\hline & & \multicolumn{3}{|c|}{ MT } & \multicolumn{3}{|c|}{ MS } & \multicolumn{3}{|c|}{ GO } \\
\hline & & Bás. & Inter. & $A v$. & Bás. & Inter. & $A v$. & Bás. & Inter. & $A v$. \\
\hline \multirow{2}{*}{ Investimento } & Inicial & 100 & 100 & - & 100 & 100 & - & 100 & 100 & - \\
\hline & Execução de projetos & 100 & 100 & 87,5 & 100 & 100 & - & 100 & 100 & - \\
\hline \multirow{3}{*}{$\begin{array}{l}\text { Operação/ } \\
\text { Produção }\end{array}$} & Engenharia de processo & 100 & 100 & - & 100 & - & - & - & - & 61,5 \\
\hline & Engenharia de produto & 50 & - & - & 50 & - & - & - & 53,8 & 61,5 \\
\hline & Gestão industrial & 100 & - & - & 100 & 100 & - & - & 100 & - \\
\hline Inovação & $\begin{array}{l}\text { Capacidade de buscar inova- } \\
\text { ções de produto e processo e } \\
\text { de desenvolver } P \& D\end{array}$ & 100 & - & - & 100 & - & - & - & 76,9 & 46,2 \\
\hline $\begin{array}{l}\text { Relações com a } \\
\text { economia }\end{array}$ & $\begin{array}{l}\text { Inserção no ambiente organiza- } \\
\text { cional e institucional }\end{array}$ & 100 & - & - & - & - & - & - & 84,6 & 23,1 \\
\hline
\end{tabular}

Fonte: Dados da pesquisa. 
car (safra 2012/2013), perdendo apenas para São Paulo, tem a previsão de produzir na safra 2013/2014 mais de 58 milhões de toneladas de cana, o que equivaleria à toda a cana colhida nos estados do Nordeste e do Norte. Recentemente, foi anunciada a inauguração da Usina Rio Dourado, localizada no município de Cachoeira Dourada, considerada uma das mais modernas do País. Esta unidade terá capacidade para moer anualmente 2,5 milhões de toneladas de cana-de-açúcar, colheita $100 \%$ mecanizada, com todos os processos produtivos da indústria automatizados e controlados, 24 horas por dia, por um Centro de Operações (SIFAEG, 2014). Este exemplo é um indicador de que Goiás é o estado centro-oestino com o maior percentual de agroindústrias canavieiras direcionando investimentos na busca em inovações de produto e processo e desenvolvimento de $\mathrm{P} \& \mathrm{D}$, procurando também aperfeiçoar a trajetória tecnológica do produto e sua tática de comercialização. Este cenário está diretamente relacionado ao perfil estratégico do capital que atua neste estado em particular.

Cabe ponderar que, apesar das diferenças no contexto regional da agroindústria canavieira do Centro-Oeste, onde Goiás se destaca, no interior dos estados pesquisados convivem usinas e destilarias com diferentes níveis de capacidades tecnológicas: básico, intermediário e avançado.

\subsection{Análise da ocorrência dos menores percentuais}

Uma comparação entre os menores percentuais de ocorrências em cada estado irá revelar outro cenário, que será abordado a seguir, com o auxílio da Tabela 4 .

No que diz respeito ao dimensionamento da gradação tecnológica menos expressiva nos três estados produtores de cana-de-açúcar na região Centro-Oeste do Brasil e a sua implicação, observa-se que as áreas hachuradas indicam onde se localizam os menores percentuais de ocorrências em cada estado.

A primeira constatação é que as áreas hachuradas que destacam onde estão os menores percentuais se concentram principalmente na categoria capacidade tecnológica avançada. Destarte, é possível delinear os desafios com relação às capacidades tecnológicas que a agroindústria canavieira do Centro-Oeste ainda necessita fundamentar para traçar melhores estratégias concorrenciais, assentadas nos quatro âmbitos, de investimentos, operação/produção, inovação e de relações com a economia. Isto é, embora muitos aspectos positivos tenham sido comentados, faltam ainda elementos, no contexto geral, para que a capacidade tecnológica da agroindústria canavieira do Centro-Oeste sustente a gradação

Tabela 4. Matriz de capacidades tecnológicas da agroindústria canavieira de Mato Grosso, Mato Grosso do Sul e Goiás, segundo os menores percentuais de ocorrências em cada estado

\begin{tabular}{|c|c|c|c|c|c|c|c|c|c|c|}
\hline \multirow{3}{*}{ Âmbitos } & \multirow{3}{*}{ Perfis } & \multicolumn{9}{|c|}{ Capacidade tecnológica (\% de ocorrências) } \\
\hline & & \multicolumn{3}{|c|}{ MT } & \multicolumn{3}{|c|}{ MS } & \multicolumn{3}{|c|}{ GO } \\
\hline & & Bás. & Inter. & $A v$. & Bás. & Inter. & $A v$. & Bás. & Inter. & $A v$. \\
\hline \multirow{2}{*}{ Investimento } & Inicial & - & - & - & - & - & - & - & - & - \\
\hline & Execução de projetos & - & - & 87,5 & - & - & 12,5 & - & - & 61,5 \\
\hline \multirow{3}{*}{$\begin{array}{l}\text { Operação/ } \\
\text { Produção }\end{array}$} & Engenharia de processo & - & - & 25 & - & - & 25 & - & - & 61,5 \\
\hline & Engenharia de produto & - & 0 & - & - & 25 & - & 38,5 & - & - \\
\hline & Gestão industrial & - & - & 0 & - & - & 0 & - & - & 0 \\
\hline Inovação & $\begin{array}{l}\text { Capacidade de buscar inova- } \\
\text { ções de produto e processo e } \\
\text { de desenvolver P\&D }\end{array}$ & - & - & 12,5 & - & - & 12,5 & - & - & 46,2 \\
\hline $\begin{array}{l}\text { Relações com a } \\
\text { economia }\end{array}$ & $\begin{array}{l}\text { Inserção no ambiente } \\
\text { organizacional e institucional }\end{array}$ & - & - & 0 & - & - & 12,5 & - & - & 23,1 \\
\hline
\end{tabular}

Fonte: Dados da pesquisa. 
avançada, que é aquela que permite maior excelência competitiva.

Logo, o learning-by-searching, que abrange as atividades de busca por novas tecnologias derivadas da presença de departamentos e equipes de $\mathrm{P} \& \mathrm{D}$, internos ou não às firmas, não é uma prática usual na agroindústria canavieira do Centro-Oeste. Isto também foi observado por Shikida et al. (2011) para São Paulo, Minas Gerais e Paraná.

Sendo assim, é possível para este setor crescer, sobretudo, em departamento de $P \& D$, o que pode facilitar a criação de novas tecnologias, o patenteamento e a consequente venda de pacotes tecnológicos para terceiros. Neste sentido, sugere-se que a agroindústria canavieira possa direcionar esforços para crescer em termos de P\&D em áreas em que as inovações se originam principalmente de dentro das unidades produtivas, como nas eficiências de extração, fermentação e industrial, e na gestão (SHIKIDA, 2001). Cumpre dizer que este setor técnico-produtivo tem uma caracterização de oligopólio diferenciado-concentrado, sendo as inovações no desenho do processo básico, no desenho e fabricação dos equipamentos feitos pelos fornecedores, enquanto as inovações agrícolas são feitas comumente por centros de pesquisa, como o CTC. Ademais, convém ressaltar que a inovação em muitos setores é dominada por fornecedores (PAVITT, 1984), sem que isso caracterize perda de competitividade. Empresas fornecedoras de máquinas e equipamentos contribuíram em muito em inovação na produção de açúcar e etanol no Brasil (SHIKIDA et al., 2011).

Segundo a teoria evolucionária, o ambiente de concorrência tenderá a produzir ganhadores e perdedores, ocorrendo, então, um processo de seleção das melhores escolhas e estratégias, do qual sobreviverão somente as empresas mais aptas. Portanto, sob essa ótica, torna-se importante minimizar os custos, introduzir inovações em produtos ou processos (aproveitamento intensivo dos resíduos gerados na indústria), modernizar a estrutura organizacional das firmas, dentre outras medidas deste teor.

Verifica-se que algumas empresas da agroindústria canavieira do Centro-Oeste estão dire- cionando seus objetivos na busca por avanços e melhorias tecnológicas, sobressaindo-se das demais por apresentarem características que as conduzirão para melhores trajetórias no futuro. Entretanto, o cenário ainda é o de domínio maior das capacidades tecnológicas na gradação básica e intermediária, havendo muito espaço para crescer, mormente na gradação avançada.

Uma razão para este quadro atual das capacidades tecnológicas da agroindústria canavieira centro-oestina estar num patamar de relativo destaque, mesmo com algumas limitações, está no fato de que a dinâmica concorrencial neste segmento produtivo avançou somente com a desregulamentação setorial pós 1990. E as unidades produtivas no Centro-Oeste, em sua maioria, foram implantadas exatamente a partir dessa conjuntura, já incorporando modernos equipamentos e gestão. Ademais, vale citar que algumas usinas/destilarias nesta região de fronteira são de capital paulista e internacional, que apregoa maior busca inovativa.

\section{Conclusões}

Este estudo objetivou analisar a dinâmica tecnológica da agroindústria canavieira nos três estados do Centro-Oeste do Brasil por meio do instrumental das capacidades tecnológicas, a partir do conceito de Lall (1992), sob quatro ênfases prioritárias: no investimento; na operação/ produção; na inovação e no âmbito das relações com a economia. Para tanto, foram selecionadas para participar desta pesquisa todas as usinas e/ ou destilarias que se localizavam nos três estados produtores dessa região. Em Mato Grosso, 100\% dos entrevistados responderam ao questionário, em Mato Grosso do Sul, 54,5\% e, em Goiás, o índice de respondentes foi de $50 \%$.

Como corolário, no contexto geral observou-se que as agroindústrias canavieiras do Centro-Oeste realizam atividades básicas e rotineiras da gradação básica, tais como: estudos de viabilidade técnico-econômica, seleção do melhor local, cronograma de investimentos, construção 
de plantas, o controle da qualidade no processo de produção, levantamento e análise dos problemas, manutenção preventiva dos equipamentos, estudo geral dos métodos e dos tempos de trabalho, controle dos estoques, conhecimento mínimo da tecnologia utilizada e troca de informações com fornecedores, dentre outras.

Esta pesquisa também procurou dimensionar qual é a gradação tecnológica predominante e a menos expressiva nos três estados produtores de cana-de-açúcar na região Centro-Oeste do Brasil e qual a sua implicação. Sendo assim, conclui-se que as usinas e/ou destilarias dos três estados dominam fundamentalmente uma grande parte das capacidades tecnológicas na gradação básica e intermediária. No tocante à gradação avançada, observou-se que Goiás apresentou a maior concentração técnica, sobressaindo-se em relação a Mato Grosso e Mato Grosso do Sul em vários perfis da matriz de capacidades tecnológicas.

Constatou-se, ainda, que além de Goiás apresentar os maiores percentuais na gradação avançada no que diz respeito à matriz de capacidades tecnológicas, esse estado também superou Minas Gerais na safra 2012/2013 e se tornou o segundo maior produtor de cana-de-açúcar do Brasil, atrás apenas de São Paulo. Dados apontam que, em 2000, Goiás era responsável por 2,9\% da área plantada de cana no Brasil e tinha participação de apenas 3,1\% na produção nacional. Em 2009, essa área passou a representar $6 \%$ do total nacional e o seu market share no ranking nacional de produção de cana-de-açúcar já era de 6,5\%. Embora a revelação de dados individuais das unidades pesquisadas não seja possível, devido ao fato de que, na aplicação do questionário este item ter sido firmado, neste estudo observou-se que os capitais internacional e paulista, detentores de algumas usinas/ destilarias também no estado goiano, vêm priorizando a busca por inovações e gestão competitiva mais do que nos demais casos verificados. Com efeito, o padrão econômico-financeiro dominante deste tipo de capital impõe de certa forma um padrão tecnológico igualmente dominante.
Consequentemente, este estudo também apontou as possíveis diferenças e similaridades na matriz de capacidades tecnológicas das agroindústrias canavieiras instaladas na região Centro-Oeste. Conforme exposto, as desigualdades entre as agroindústrias canavieiras desses estados podem ser compreendidas como sendo derivadas de estratégias empresariais, que reflete em diferentes níveis de acumulação tecnológica e melhores condições concorrenciais. Sendo assim, se a expansão produtiva recente deste segmento produtivo - cada vez mais baseada em padrões técnicos e organizacionais modernos, mas ainda calcada em capacidades tecnológicas situadas, sobretudo, na gradação básica e intermediária - apoiar-se em novas soluções tecnológicas concentradas na gradação avançada, a competitividade da região Centro-Oeste no contexto da economia canavieira será potencializada. Contudo, o cenário atual de desregulamentação setorial impõe uma nova institucionalidade privada e pública, que possa combinar interesses nem sempre congruentes, seja por parte do Estado, seja por parte das usinas. Outrossim, aspectos como o desenho do processo básico, desenho e fabricação dos equipamentos, não são estrategicamente de competência das usinas e destilarias, sendo feitos pelo setor a montante deste segmento. E o CTC e outras instituições de pesquisa também atuam de forma a dinamizar a P\&D do setor agrícola da economia canavieira. Desse modo, investimentos em P\&D serão mais producentes onde o learning-by-doing das unidades produtivas for propício para isto, como nas eficiências de extração, fermentação e industrial, com alcance também na gestão.

Finalizando, este estudo sugere que no futuro próximo possam ser realizados outros trabalhos acerca da agroindústria canavieira, destacando o Centro-Oeste, que ainda é carente de pesquisas sobre este segmento. Isto é, podem ser traçados, mediante distintas opções metodológicas, outros desafios da agroindústria canavieira nesta região de fronteira, contribuindo para o entendimento e desenvolvimento deste importante setor da economia brasileira. 


\section{Referências bibliográficas}

ANDRADE, M. C. de. Modernização e pobreza: a expansão da agroindústria canavieira e seu impacto ecológico social. São Paulo. Editora da UNESP, 1994.

BELL, M. Learning and the accumulation of industrial technological capacity in developing countries. In: FRANSMAN, M. e KING, K. Technological capability in the Third World. London: Macmillan, 1984, p. 187-209.

. e PAVITT, K. Technological accumulation and industrial growth: contrast between developed and developing countries. Industrial and corporate change, v. 2, n. 2, p. 157-210, 1993.

BUAINAIN, A. M. et al. Sete teses sobre o mundo rural brasileiro. Revista de Política Agrícola, Brasília-DF, v.22, n. 2, p. 105-121, abr.jun. 2013.

CANUTO, O. Ciclos de vida do produto e vantagens de internacionalização de capacidades tecnológicas, sob uma abordagem evolucionista. In: ENCONTRO NACIONAL DE ECONOMIA, 19., Curitiba, 1991. Anais. Brasília: ANPEC, 1991, p. 313-334.

CÁRIO, S. A. F. e PEREIRA, F. C. B. Inovação e desenvolvimento capitalista: referência histórica e conceitual de Schumpeter e dos Neo-Schumpeterianos para uma teoria econômica dinâmica. Revista de Ciências Humanas Universidade do Extremo Sul Catarinense, Criciúma/SC, v. 7, n. 1, p. 81-102, 2001.

CASSIOLATO, J. E. e LASTRES, H. M. M. Sistemas de inovação: políticas e perspectivas. Parcerias Estratégicas, n. 17, p. $5-30,2000$.

CENTRO DE TECNOLOGIA CANAVIEIRA (CTC). A nossa cana é o nosso mundo, 2013. Disponível em: $<$ http:// www.ctcanavieira.com.br/index.html>. Acesso em: 15 dez. 2013.

COMPANHIA NACIONAL DE ABASTECIMENTO (CONAB). Acompanhamento da safra brasileira. Cana-de-açúcar: Primeiro levantamento abril 2013. Disponível em: < http://www.conab.gov.br/OlalaCMS/ uploads/arquivos/13_04_09_10_29_31_boletim_cana_ portugues_abril_2013_1o_lev.pdf > . Acesso em: 08 mai. 2013.

CORAZZA, R. I. e FRACALANZA, P. S. Caminhos do pensamento neo-schumpeteriano: para além das analogias biológicas. Nova Economia, Belo Horizonte, v. 14, n. 2, p. 127-155, mai./ago. 2004.

COSTA, R. M., CHRYSOSTHEMOS, R. N. e ALVES, F. J. da C. Aspectos históricos e políticos da expansão dos Pólos Agroindustriais da cana-de-açúcar no Estado de
Mato Grosso, Brasil. In: CONGRESSO BRASILEIRO DE ECONOMIA E SOCIOLOGIA RURAL, XLVIII, Campo Grande (MS), 2010. Anais. MS: SOBER, 2010.

COUTINHO, L. e FERRAZ, J. C. (Coords.). Estudo da competitividade da indústria brasileira. Campinas: Unicamp/Papirus, 1994.

DAHLMAN, C., ROSS-LARSON, B. e WESTPHAL, L. Managing technological development - lessons from the newly industrializing countries. Washington: World Bank Staff - Working Papers, n. 717, 1985.

. e WESTPHAL, L., Technological effort in industrial development: an interpretative survey of recent research. In: STEWART, F. e JAMES, J. (Orgs.). The economics of new technology in developing countries, Londres: Frances Pinter, 1982, p. 105-137.

DOSI, G. Sources, procedures and microeconomics effects of innovation. Journal of Economic Literature. Pittsburgh, PA: American Economic Association, v. 26, n. 3, p. 1120-1171, set. 1988.

. Technical change and industrial transformation. New York: St. Martin's Press, 1984.

.; FREEMAN, C. The diversity of devepeloment patterns: on the process of the catching-up, forging ahead, and falling behind. In: Conference on Economic Growth and the Structure of Long-term Development, Varenna, Oct. 1-3, 1992.

DRUCKER, P. F. Inovação e espírito empreendedor (entrepreneurship): práticas e princípios. São Paulo: Pioneira, 1986.

FONSECA, J. J. S. Metodologia da pesquisa científica. Fortaleza: UEC, 2002. Apostila.

GERHARDT, T. E. e SILVEIRA, D. T. Métodos de pesquisa. Porto Alegre: Editora UFRGS, 2009.

GIL, A. C. Técnicas de pesquisa em economia e elaboração de monografias. São Paulo: Atlas, 2000.

GITMAN, L. J. Princípios de administração financeira. 7aㅡ ed. São Paulo: Harbra, 1997.

HOFFMANN, R. e VIEIRA. S. Análise de regressão: uma introdução à econometria. 2. ed. São Paulo: HUCITEC, 1987.

INSTITUTO BRASILEIRO DE GEOGRAFIA E ESTATÍSTICA (IBGE). Censo Demográfico 2010. 2014. Disponível em: < http://censo2010.ibge.gov.br/> . Acesso em: 02 jan. 2014.

LALL, S. Technological Learning in the Third World: Some Implications of Technology Exports. In: STEWART, F. e JAMES, J. (Orgs.). The economics of new 
technology in developing countries. Londres: Frances Pinter, 1982.

Learning to industrialize: the acquisition of technological capability by India. London: Macmillan, 1987.

Technological capabilities and industrialization. World Development, v. 2, n. 20, p. 165-186, fev. 1992. Disponível em: <http://www.unu.edu/unupress/ unupbooks/>. Acesso em: 02 abr. 2013.

LIFSCHITZ, J. e BRITO, J. N. P. Inovação tecnológica, padrões de difusão e diversificação: uma resenha da literatura. Rio de Janeiro: UFRJ/IEI, 1992. (Texto para discussão).

MARTINS, J. P. e SHIKIDA, P. F. A. Matriz de capacidades tecnológicas como approach teórico para estudo de caso: notas e observações. Revista de Economia e Administração, São Paulo (SP), v. 4, n. 1, p. 97-117, jan./mar. 2005.

MICHELLIM, D. D. Análise da matriz de capacidades tecnológicas do D1 sucroalcooleiro. 2012. 54 f. Monografia (Ciências Econômicas) - USP/ESALQ. Piracicaba, 2012.

MUNHOZ, D. G. Economia aplicada: técnicas de pesquisa e análise econômica. Brasília: Editora Universidade de Brasília, 1989.

NELSON, R. e WINTER, N. An evolutionary theory of economic change. Cambridge, Mass: Harvard University Press, 1982.

NORONHA, S. e ORTIZ, L. (Coord.). Agronegócio e biocombustíveis: uma mistura explosiva - impactos da expansão das monoculturas para a produção de bioenergia. Rio de Janeiro: Núcleo Amigos da Terra/ Brasil, 2006.

PAVITT, K. Sectoral patterns of technical change: towards a taxonomy and a theory, Research Policy, v. 6, n. 13, p. 343-373, 1984.

POSSAS, M. L. Concorrência, inovação e complexos industriais: algumas questões conceituais. Cadernos de Ciência \& Tecnologia, Brasília, v. 8, n. 1/3, p. 78-97, jan./ dez. 1991.

RAMOS, P. Heterogeneidade e integração produtiva na evolução recente da agroindústria canavieira do Centro-Sul (1985-2000). In: MORAES, M. A. F. D. de e SHIKIDA, P. F. A. (Orgs). Agroindústria canavieira no Brasil: evolução, desenvolvimento e desafios. São Paulo: Atlas, 2002. p. 241-262.

ROSENBERG, N. Inside the black box: technology and economics. Cambridge: Cambridge University Press, 1982.
SCHMIDT, C. M. Cultura empreendedora: contribuição para o arranjo produtivo local de turismo sustentável da Nova Rússia, Blumenau, SC. 2006. 135 p. Dissertação (Mestrado em Administração) - FURB, Blumenau, SC, 2006.

SCHUMPETER, J. Capitalismo, socialismo e democracia. Rio de Janeiro: Fundo de Cultura, 1961 (para a tradução brasileira). 1942.

. Teoria do desenvolvimento econômico. São Paulo: Nova Cultural, 1985.

SHIKIDA, P. F. A. A dinâmica tecnológica da agroindústria canavieira do Paraná: estudos de caso das Usinas Sabarálcool e Perobálcool. Cascavel: Edunioeste, 2001.

. Expansão canavieira no Centro-Oeste: limites e potencialidades. Revista de Política Agrícola, Brasília-DF, v. 22, n. 2, p. 122-137, abr.juun. 2013.

AZEVEDO, P. F. de e VIAN, C. E. de F. Desafios da agroindústria canavieira no Brasil pósdesregulamentação: uma análise das capacidades tecnológicas. Revista de Economia e Sociologia Rural, Piracicaba, v. 49, n. 3, p. 599-628, jul./set. 2011.

SIFAEG - Sindicato da Indústria de Fabricação de Etanol do Estado de Goiás. Informe SIFAEG. 2014. Disponível em: <http://www.sifaeg.com.br/xtimeline/ sjc-bioenergia-inaugura-usina-de-etanol-maismoderna-do-pais/>. Acesso em: 06 de jan. 2014.

SIQUEIRA, P. H. L. Estratégias de crescimento e de localização da agroindústria canavieira brasileira e suas externalidades. 2013. 189 p. Tese (Doutorado em Dinâmica e Gestão de Cadeias Produtivas), UFLA/MG, Lavras, 2013.

SOUZA, E. C. de, SHIKIDA, P. F. A. e MARTINS, J. P. Uma análise da agroindústria canavieira do Paraná à guisa da matriz de capacidades tecnológicas. Revista de Economia e Agronegócio, Viçosa, v. 3, n.3, p. 349-375, jul./set. 2005.

TERCI, E. T. et al. Impacto das transformações e do progresso técnico sobre os fornecedores de cana dos estados de São Paulo e Paraná. In: I SEMINÁRIO DE HISTÓRIA DO AÇÚCAR: HISTORIA E CULTURA MATERIAL - CANAVIAIS, ENGENHO E AÇÚCAR. Itu (SP), 2005. Anais. São Paulo: USP, 2005.

TIGRE, P. B. Paradigmas tecnológicos e teorias econômicas da firma. Revista Brasileira de Inovação, Rio de Janeiro, v. 4, n. 1, p. 187-224, jan./jun. 2005.

TORQUATO, S. A., MARTINS, R. e RAMOS, S. F. Cana-de-açúcar no Estado de São Paulo de eficiência econômica das regionais novas e tradicionais de produção. Informações Econômicas, São Paulo, v. 39, n. 5, p. 92-99, maio 2009. 
178 - Análise da Agroindústria Canavieira nos Estados do Centro-Oeste do Brasil a partir da Matriz de Capacidades Tecnológicas

UNICA - União da Indústria de Cana-de-Açúcar. Notícias, 2014a. Disponível em: <http://www.unica. com.br>. Acesso em: 02 jan. 2014.

UNICA - União da Indústria de Cana-de-açúcar. Unicadata, 2014b. Disponível em: < http://www. unicadata.com.br>. Acesso em: 11 jan. 2014.
VIAN, C. E. de F. Agroindústria canavieira: estratégias competitivas e modernização. Campinas: Átomo, 2003.

ZAWISLAK, P. A. Uma abordagem evolucionária para a análise de casos de atividade de inovação no Brasil. Ensaios FEE, Porto Alegre, v. 17, n. 1, p. 323354, 1996. 